\title{
Incidence of vitamin $D$ deficiency rickets among Australian children: an Australian Paediatric Surveillance Unit study
}

\section{Craig F Munns MB BS, PhD, FRACP Endocrinologist \\ Peter J Simm MB BS, MD, FRACP Bone and Mineral Fellow; currently, Endocrinologist ${ }^{2,3}$ \\ Christine P Rodda MB BS, PhD, FRACP Endocrinologist \\ Sarah P Garnet BSc, MNutrDiet, PhD Research Dietician \\ Margaret R Zacharin MB BS, FRACP Endocrinologist \\ Leanne M Ward MD, FRCPC Endocrinologist \\ Janet Geddes MB BS, PhD, FRACP Paediatrician \\ Sarah Cherian MB BS, PhD, FRACP. Paediatrician \\ Yvonne Zurynsk BAppSc, MAppSc, PhD, Assistant Director \\ Christopher T Cowell MB, FRCP, FRACP Endocrinologist \\ on behalf of the APSL Vitamin D Study Group \\ 1 Institute of Endocrinology and Diabetes, Children's Hospital at Westmead Sydney, NSW. \\ 2 Paediatric Endocrinology and Diabetes Unit, Monash Children's, Melbourne, VIC \\ 3 Department of Endocrinology an Diabetes, Royal Children's Hospital, Melbourne, VIC \\ 4 Children's Hospital of Eastern Ontario, Ottawa, Ontario, Canada. $\mathbf{5}$ Department of Paediatrics and Adolescent Medicine, Princess Margare Hospital, Perth, WA. \\ 6 Australian Paediatric Surveillance Unit, Children's Hospital at Westmead. Sydney, NSW. \\ craigm2@chw.edu.au}

MJA 2012; 196: 466-468 doi: 10.5694/mjall.10662 itamin D is crucial for skeletal development, and vitamin $\mathrm{D}$ deficiency can lead to rickets, poor linear growth, motor delay, bone fragility and hypocalcaemic seizures. ${ }^{1-3}$ Most vitamin D is synthesised in the skin after exposure to ultraviolet B rays from direct sunlight, with dietary sources contributing little. ${ }^{3,4}$ Vitamin D deficiency and associated rickets are reemerging as major public health issues worldwide, including in Australia.

Accepted definitions of vitamin D deficiency are: mild, 25-hydroxyvitamin D (25OHD) level 25.1-50.0 nmol/L; moderate, $12.5-25.0 \mathrm{nmol} / \mathrm{L}$; and severe, less than $12.5 \mathrm{nmol} / \mathrm{L}^{1}$ When vitamin $\mathrm{D}$ deficiency is associated with increased bone turnover, alkaline phosphatase level is elevated (biochemical rickets). In growing bone, features of radiological rickets include widening of the growth plate, and metaphyseal splaying and cupping. Our study aimed to assess vitamin D deficiency with rickets, rather than vitamin $\mathrm{D}$ deficiency alone.

We aimed to estimate the incidence of vitamin $\mathrm{D}$ deficiency rickets among children aged 15 years and younger living in Australia, and to describe factors associated with vitamin D deficiency rickets. We used national prospectively collected data with active reporting by paediatricians and child health specialists to the Australian Paediatric Surveillance Unit (APSU).

\section{Methods}

The APSU facilitates a national active surveillance system for rare childhood conditions, with about 1260 reporting clinicians ( $84 \%$ paediatricians). ${ }^{5}$ Monthly report cards are returned with a response rate greater than $95 \% .^{5}$ Vitamin D deficiency rickets was studied from January 2006 to July 2007.

All case notifications were followed up via questionnaire to obtain demographic, clinical and biochemical data. Pregnancy, birth and breastfeeding

\begin{abstract}
Objective: To determine the incidence of and factors associated with vitamin $D$ deficiency rickets in Australian children.
\end{abstract}

Design: 18-month questionnaire-based prospective observational study, using Australian Paediatric Surveillance Unit (APSU) data.

Setting: Australian paediatricians and child health workers, January 2006 July 2007.

Participants: Children aged $\leqslant 15$ years with vitamin $D$ deficiency rickets (25-hydroxyvitamin D [25OHD] $\leqslant 50 \mathrm{nmol} / \mathrm{L}$, and elevated alkaline phosphatase levels [> $229 \mathrm{IU} / \mathrm{L}$ ] and/or radiological rickets).

Main outcome measures: Incidence of vitamin D deficiency rickets. Description of demographics, clinical presentation, identification and further analysis of overrepresented groups, and treatment regimens compared with best-practice guidelines.

Results: We identified 398 children with vitamin D deficiency (55\% male; median age, 6.3 years [range, $0.2-15$ years]). The overall incidence in children $\leqslant 15$ years of age in Australia was 4.9/100 000/year. All had a low 250HD level (median, $28 \mathrm{nmol} / \mathrm{L}$ [range, 5-50 nmol]) and an elevated alkaline phosphatase level (median, 407 IU/L [range, 229-5443IU/L]), and 48 (12\%) were hypocalcaemic. Ninety-five children had wrist x-rays, of whom $67(71 \%)$ had rachitic changes. Most (98\%) had dark or intermediate skin colour and $18 \%$ of girls were partially or completely veiled. Most children were born in Africa (252; $63 \%$ ) and $75 \%$ of children were refugees. Duration of exclusive breastfeeding was inversely related to serum vitamin $\mathrm{D}$ levels in children $<3$ years of age. Empirical vitamin D treatment was given to $4 \%$ of children before diagnosis.

Conclusions: Vitamin D deficiency rickets is a significant problem in Australia among known high-risk groups. Public health campaigns to prevent, identify and treat vitamin $D$ deficiency, especially in high-risk groups, are essential.

data were collected for children younger than 3 years of age. Inclusion criteria were: children aged $\leqslant 15$ years with vitamin $\mathrm{D}$ deficiency rickets $(25 \mathrm{OHD} \leqslant 50 \mathrm{nmol} / \mathrm{L}$, and elevated alkaline phosphatase levels as per local pathology service reference values and/or radiological rickets). Exclusion criteria were vitamin D deficiency rickets associated with an underlying chronic disease and all genetic forms of rickets. Data were collated by APSU staff and reviewed by a paediatric endocrinologist (CFM). Socioeconomic status was estimated using the Socio-Economic Indexes For Areas (SEIFA). ${ }^{6}$ Ethics approval was granted by the Human Research Ethics Committee of the Children's Hospital at Westmead.

\section{Statistical analysis}

Data were analysed and assessed for normality using SPSS, version 18 (IBM, Armonk, NY, USA). Descriptive data are presented as mean (SD) or median (range). Differences between groups were assessed using the Mann-Whitney U test (two groups) or the Kruskal-Wallis test (three groups). Association between length of breastfeeding and serum 25OHD level was assessed using Spearman rank correlation (coefficient denoted as $\rho$ ). Australian state-based population figures for children $<15$ years, which were age- and sex-standardised, ${ }^{7}$ were used to estimate the incidence of simple vitamin D deficiency per year. Comparisons of incidences was performed using the StatXact, version 4 (Cytel Inc, Cambridge, Mass, USA) difference in two binomial proportions test (asymptotic method).

\section{Results}

Between January 2006 and July 2007, there were 851 notifications of vitamin 
D deficiency rickets to the APSU; 453 of these were either duplicate notifications or did not meet the inclusion criteria. Of the remaining 398 children (219 [55\%] male; median age, 6.3 years [range, $0.2-15$ years]), 36 (9\%) were classified as having severe vitamin D deficiency, 155 (39\%) as moderate and 207 (52\%) as mild.

The estimated national annual incidence of vitamin $\mathrm{D}$ deficiency rickets among children was 4.9/100000 children (95\% CI, 4.4-5.4/100 000). There were 251 children from Victoria, or $13.0 / 100000$ per year (95\% CI, 11.314.6/100 000; $P<0.001)$; and 69 from Western Australia, or 8.4/100 000 (95\% CI, 6.5-10.6/100000; $P<0.001)$. The annual incidence for New South Wales was significantly lower than the national incidence: 70 children, or $2.6 /$ 100000 (95\% CI, 2.0-3.3/100 000; $P<0.001)$. There were eight cases from South Australia, Queensland, the Northern Territory, the Australian Capital Territory and Tasmania. The median age at diagnosis was 6.24 years (range, $0.1-15.0$ years) and there was a small difference in annual incidence (standardised difference: - 1.3/100 000; $P<0.05)$ between children aged $0-4$ years (153 children; incidence, 5.9/ 100000 [95\% CI, 4.9-6.9/100 000]) and children aged 5-14 years (245 children; incidence, 4.5/100000 [95\% CI, 3.9$5.1 / 100000])$. Postcode data were available for 371 children. Children were evenly distributed in areas of relative socioeconomic disadvantage (SEIFA 1-5, 179 [48\%]) and advantage (SEIFA 6-10, 192 [52\%]). Most patients $(297 ; 75 \%)$ were refugees, and vitamin $\mathrm{D}$ deficiency rickets was most commonly detected by abnormal biochemical results on routine screening through refugee clinics.

The presenting symptoms are summarised in Box 1. Biochemical features are outlined in Box 2. Data from wrist x-rays were available for 95 children, of whom 67 (71\%) showed radiological rickets. The median $25 \mathrm{OHD}$ level was not statistically different between cases with radiological rickets, $18 \mathrm{nmol} / \mathrm{L}$ (range, 5-45 nmol/L), and those without, $20 \mathrm{nmol} / \mathrm{L}$ (range, $8-45 \mathrm{nmol} / \mathrm{L}$ ) $(P=0.074)$.

Presentation demonstrated a seasonal variation, with 240 cases $(60 \%)$ identified in winter and spring, compared with 158 (40\%) in summer and autumn (Box 3).
Nine children had been born prematurely. Breastfeeding data were collected for 96 of the 134 children who were younger than 3 years of age at diagnosis. The median duration of exclusive breastfeeding was 6.0 months (range, 1.5-24.0 months), with an inverse association between the length of time of exclusive breastfeeding and serum 25OHD $(\rho=-0.20, P=0.05)$.

Most patients were born in Africa (252; 63\%), and 94 (24\%) were born in Australia (Box 4). Skin colour of mothers was similar to those reported for children, which were "dark" in $85 \%$, "intermediate" in $13 \%$ and "fair" in $2 \%$. One hundred and fortytwo children (36\%) and almost half the children's parents (47\%) were born in Sudan. The annual incidence for patients of Sudanese background was estimated to be 2300/100 000 350 times greater than the national estimated incidence.

One hundred and four of 338 (31\%) mothers were veiled during pregnancy. Mothers who reported being consistently covered during pregnancy (30/104) had children with lower median serum concentrations of $25 \mathrm{OHD}$ at diagnosis than mothers who reported inconsistent covering (74/104) (consistently veiled, median, $22 \mathrm{nmol} / \mathrm{L}$ [range, 9-42 $\mathrm{nmol} / \mathrm{L}$ ] V inconsistently veiled, median $29 \mathrm{nmol} / \mathrm{L}$ [range, $10-47 \mathrm{nmol} / \mathrm{L}$ ]; $P=$ 0.001 ), and their children were diagnosed at an earlier age (consistently veiled, median, 2.7 years [range, 2 months - 12 years] $\mathrm{v}$ inconsistently veiled, median 7.4 years [ 1 month -15 years]; $P=0.001)$. There was no difference between those who reported intermittent covering and those who were uncovered.

Data on veiling were available for $158 / 179$ girls $(88 \%) ; 29$ were veiled $(18 \%)$ and 129 not veiled (82\%); there was no difference in median
25OHD levels (veiled, $28 \mathrm{nmol} / \mathrm{L}$ [range, 9-47 nmol/L] v non-veiled, $26 \mathrm{nmol} / \mathrm{L}$ [10-47 nmol/L]; $P=0.70)$.

Treatment after diagnosis was recorded for 361 children (91\%); 216 children were administered intermittent megadose ("stoss") vitamin D therapy, 75000-150000 units per dose, repeated up to three times, and 145 patients used daily dosing regimens of $800-5000$ units daily. Total vitamin $\mathrm{D}$ dose administered to all children was between 72000 and 450000 units over the treatment course. Empirical vitamin D treatment was given to $4 \%$ of children before diagnosis.

\section{Discussion}

This is the first study to assess the incidence of vitamin D deficiency rickets in Australian children. Our data confirmed that recent migrants, especially those with dark skin, had a significantly higher incidence of vitamin D deficiency rickets than the overall Australian paediatric population. Sudan was the most common country of birth for children and parents in this study, which reflected the targeted humanitarian refugee intake into Australia over the study period. ${ }^{8}$

1 Reason for presentation of cases identified with simple vitamin $D$ deficiency rickets

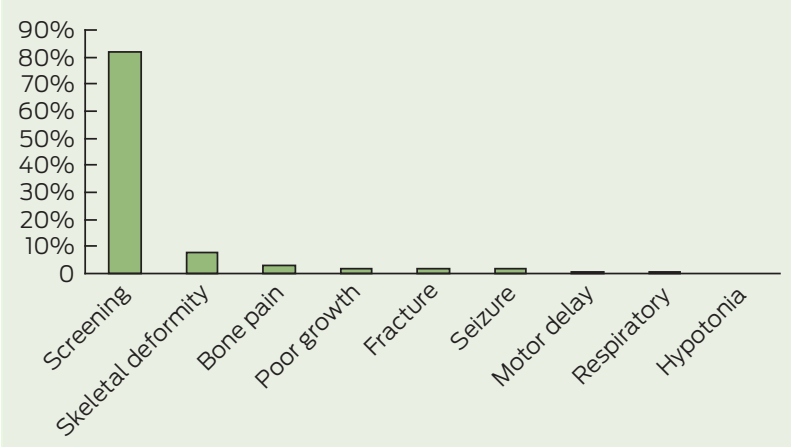

2 Biochemical analysis of children identified with simple vitamin D deficiency

\begin{tabular}{lcccc} 
& $\begin{array}{c}\text { No. of } \\
\text { children }\end{array}$ & Reference range & Median (range) & $\begin{array}{c}\text { Above/below cut } \\
\text { point, no. (\%) }\end{array}$ \\
\hline 25-hydroxyvitamin D, nmol/L & 398 & $>50$ & $28(5-50)$ & $398(100 \%)$ \\
Alkaline phosphatase, IU/L & 393 & $80-325 *$ & $407(229-5443)$ & $398(100 \%)$ \\
Calcium, mmol/L & 358 & $2.10-2.65$ & $2.38(1.22-2.94)$ & $48(12 \%)$ \\
Phosphorus, mmol/L & 328 & $1.00-1.80$ & $1.69(0.16-2.78)$ & $28(7 \%)$ \\
Parathyroid hormone, pmol/L & 170 & $1.0-7.0$ & $6.85(0.8-99.1)$ & $195(49 \%)$ \\
\hline
\end{tabular}

* Quoted reference range for the Children's Hospital at Westmead laboratory. Local laboratory quoted reference ranges varied, leading to $100 \%$ incidence of elevated alkaline phosphatase levels. 
Seasonal variation was observed, with increased incidence in late winter/ spring that decreased over summer. The effect of latitude was also important, with Victoria's reported incidence nearly five times that of NSW. The populations at risk are likely to differ between states and regions, which may also effect reporting rates.

Maternal vitamin D deficiency has been shown to be a risk factor for deficiency in infants, ${ }^{9}$ and we found that consistent veiling among mothers was associated with more severe vitamin D deficiency and earlier presentation of paediatric vitamin D deficiency. These data support the current recommendations that women of childbearing age who are at risk of vitamin $\mathrm{D}$ deficiency should have routine vitamin $\mathrm{D}$ screening during

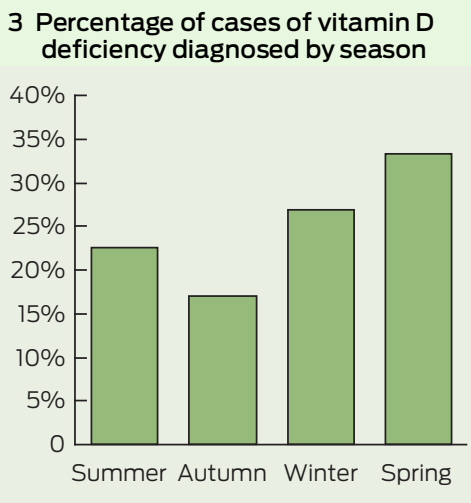

Summer = January - March. Autumn = AprilJune. Winter = July-September. Spring = October-December. pregnancy and receive appropriate supplementation. ${ }^{1}$ Breast milk is widely recognised as the most appropriate food for babies, but it contains very little vitamin $\mathrm{D}^{10}$ and prolonged breastfeeding is associated with vitamin D deficiency rickets. ${ }^{11}$ However, most cases were in children over 5 years of age.

Although our study provides the first national estimate of vitamin D deficiency rickets, it is likely that there was underreporting of cases leading to an underestimate of the true incidence of vitamin D deficiency rickets. Another limitation is that the sample analysed may be biased, given that most cases were reported from services such as refugee health clinics with an increased awareness of the importance of vitamin $\mathrm{D}$ deficiency rickets and routine screening protocols. Further, there is significant variation observed between commercially available vitamin D assays. ${ }^{12}$

Soon after the commencement of this study, an Australian and New Zealand consensus statement on the prevention and treatment of infant and childhood vitamin D deficiency was published. ${ }^{1}$ Although the vast majority of children in our study received vitamin $\mathrm{D}$ therapy within the recommended guidelines to treat established rickets, ${ }^{1}$ attention to routine screening and supplementation to prevent vitamin $\mathrm{D}$ deficiency are required. Further public health campaigns are

\section{Country of birth of children with vitamin D deficiency rickets and their parents}

\begin{tabular}{|lccc}
$\begin{array}{l}\text { Child's country } \\
\text { of birth }\end{array}$ & No. of children (\%) & $\begin{array}{c}\text { Parents' country } \\
\text { of birth* }\end{array}$ & No. of parents (\%) \\
\hline Sudan & $142(35.9)$ & Sudan & $363(47.3)$ \\
\hline Australia & $94(23.6)$ & Somalia & $98(12.8)$ \\
\hline Egypt & $31(7.7)$ & Ethiopia & $44(5.7)$ \\
\hline Kenya & $28(6.9)$ & Eritrea & $34(4.4)$ \\
\hline Ethiopia & $20(4.9)$ & Afghanistan & $22(2.9)$ \\
\hline Tanzania & $13(3.1)$ & India & $20(2.6)$ \\
\hline Somalia & $11(2.8)$ & Burundi & $18(2.3)$ \\
\hline Burma & $7(1.8)$ & Kenya & $18(2.3)$ \\
\hline Afghanistan & $5(1.3)$ & Liberia & $17(2.2)$ \\
\hline Congo & $5(1.3)$ & Burma & $16(2.1)$ \\
\hline Eritrea & $4(1.0)$ & Congo & $15(2.0)$ \\
\hline Uganda & $4(1.0)$ & Australia & $11(1.4)$ \\
\hline Thailand & $4(1.0)$ & Pakistan & $9(1.2)$ \\
\hline Other (13 Africa) & $30(7.7)$ & Other (9 Africa) & $82(10.7)$ \\
\hline Total & $398(100)$ & Total & 767 \\
\hline * Data available on 385 mothers and 382 fathers. & & \\
\hline
\end{tabular}

also needed to increase awareness of vitamin D deficiency in at-risk groups.

Acknowledgements: In addition to the authors, members of the APSU Vitamin D Study Group include David P Burgner, Elizabeth Davis, Mark Harris, Jennifer Batch, Mark Pascoe, Jan Fairchild, Anthony Lafferty, Annie Whybourne, Ruth Morley and Julieta Solis-Chacon. APSU activities are supported by the Australian Government Department of Health and Ageing; National Health and Medical Research Council (Enabling Grant No. 402784 and Practitioner Fellowship No. 457084, E. Elliott); the Discipline of Paediatrics and Child Health and Faculty of Medicine, University of Sydney; the Children's Hospital at Westmead, and the Royal Australasian College of Physicians. We thank all clinicians who participate in APSU surveillance.

Competing interests: Craig Munns received financial support from Bayer Australia to enable the study to be performed through the APSU. Bayer Australia were not involved in study design, data analysis or interpretation of results.

Received 27 May 2011, accepted 15 Dec 2011.

1 Munns C, Zacharin MR, Rodda CP, et al. Prevention and treatment of infant and childhood vitamin D deficiency in Australia and New Zealand: a consensus statement. Med J Aust 2006; 185: 268-272.

2 Holick MF. Resurrection of vitamin D deficiency and rickets. J Clin Invest 2006; 116: 2062-2072.

3 Holick MF. Vitamin D deficiency. NEngl J Med 2007; 357: 266-281

4 Lips P. Vitamin D physiology. Prog Biophys Mol Biol 2006; 92: 4-8.

5 He S, Zurynski YA, Elliott EJ. Evaluation of a national resource to identify and study rare diseases: the Australian Paediatric Surveillance Unit. J Paediatr Child Health 2009; 45: 498-504.

6 Australian Bureau of Statistics. Census of Population and Housing: Socio-Economic Indexes for Areas (SEIFA) - data only, 2006 Canberra: ABS, 2006. (ABS Cat. No. 2033.0.55.001.) http://www.abs.gov.au/ ausstats/abs@.nsf/mf/2033.0.55.001 (accessed Nov 2010).

7 Australian Bureau of Statistics. Australian demographic statistics. September quarter 2009. Canberra: ABS, 2010. (ABS Cat. No. 3101.0.) http://www.ausstats.abs.gov.au/ausstats/ subscriber.nsf/0/ 26D01CDE59A47371CA2576F0001C7F50/\$File/ 31010_sep\%202009.pdf (accessed Nov 2010).

8 Australian Government Department of Immigration and Citizenship. Immigration update 2006-2007. Canberra: DIC, 2008. http:// www.immi.gov.au/media/publications/ statistics/immigration-update/update_ june07.pdf (accessed Nov 2010).

9 Thomson K, Morley R, Grover SR, Zacharin MR. Postnatal evaluation of vitamin $D$ and bone health in women who were vitamin D-deficient in pregnancy, and in their infants. Med J Aust 2004; 181: 486-488

10 Gartner LM, Greer FR; Section on Breastfeeding and Committee on Nutrition. American Academy of Pediatrics. Prevention of rickets and vitamin D deficiency: new guidelines for vitamin $D$ intake. Pediatrics 2003; 111: 908-910.

11 Ward LM, Gaboury I, Ladhani M, Zlotkin S. Vitamin D-deficiency rickets among children in Canada. CMAJ 2007; 177: 161-166.

12 Snellman G, Melhus H, Gedeborg R, et al. Determining vitamin D status: a comparison between commercially available assays. PLoS One 2010; 5: el1555. 